\title{
GEOMETRIC EVALUATION OF FOUR STAGGERED CYLINDERS ARRAY SUBJECTED TO FORCED CONVECTIVE FLOWS BY MEANS OF CONSTRUCTAL DESIGN
}

\author{
A. P. D. Aghenese, \\ F. B. Teixeira ${ }^{\text {, }}$ \\ L. A. O. Rocha', \\ L. A. Isoldi ${ }^{\mathrm{a}}$, \\ J. F. P. Filho ${ }^{a}$, \\ and E. D. dos Santos ${ }^{\mathrm{a}}$ \\ ${ }^{a}$ Universidade Federal do Rio Grande \\ Programa de Pós-grad. em Modelagem Computacional \\ Escola de Engenharia \\ CEP 96201-900, Rio Grande, RS, Brasil \\ anapauladelaghenese@hotmail.com \\ liercioisoldi@furg.br \\ joaoprolo@furg.br \\ elizaldosantos@furg.br

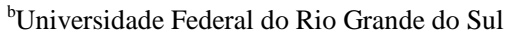 \\ Programa de Pós-graduação em Eng. Mecânica \\ CEP 90050-170, Porto Alegre, RS, Brasil \\ fbrancoteixeira@gmail.com \\ 'Universidade do Vale do Rio dos Sinos \\ Programa de Pós-graduação em Eng. Mecânica \\ CEP 93022-750, São Leopoldo, RS, Brasil \\ luizor@unisinos.br

\section{ABSTRACT}

\section{NOMENCLATURE} \\ A Area, $\mathrm{m}^{2}$ \\ $\mathrm{A}_{\mathrm{o}} \quad$ Occupation area of cylinders, $\mathrm{m}^{2}$ \\ $\mathrm{A}_{\mathrm{T}} \quad$ Total area of cylinders, $\mathrm{m}^{2}$ \\ $C_{D} \quad$ Drag coefficient \\ $\mathrm{C}_{\mathrm{P}} \quad$ Specific heat coefficient at constant pressure, \\ $\mathrm{J} / \mathrm{kg} \cdot \mathrm{K}$ \\ D Diameter of cylinders, $\mathrm{m}$ \\ $F_{D} \quad$ Drag force, $N$ \\ g Acceleration of gravity field, $\mathrm{m} / \mathrm{s}^{2}$ \\ h Convection heat transfer coefficient, $\mathrm{W} / \mathrm{m}^{2} . \mathrm{K}$ \\ $\mathrm{H} \quad$ Computational domain height, $\mathrm{m}$ \\ $\mathrm{H}_{\mathrm{o}} \quad$ Height of occupation area of cylinders, $\mathrm{m}$ \\ $\mathrm{k}$ Thermal conductivity of the fluid, W/m.K \\ $\mathrm{L} \quad$ Length of computational domain, $\mathrm{m}$ \\ $\mathrm{L}_{1} \quad$ Distance between inlet domain and the center \\ of first cylinder, $\mathrm{m}$ \\ $\mathrm{L}_{\mathrm{o}} \quad$ Length of occupation area of cylinders, $\mathrm{m}$ \\ $\mathrm{Nu}_{\mathrm{D}} \quad$ Nusselt number, $\mathrm{hD} / \mathrm{k}$ \\ $\mathrm{P} \quad$ Pressure, $\mathrm{N} / \mathrm{m}^{2}$ \\ Pr Prandtl number, $v / \alpha$
}

This work presents a numerical study on the geometric evaluation of forced convective flows over four staggered arrangement of four cylinders. The forced convective flow is considered incompressible, two-dimensional, laminar and unsteady. Geometry varies according to Constructal Design method. The objectives are the maximization of Nusselt number $\left(\mathrm{Nu}_{\mathrm{D}}\right)$ and minimization of drag coefficient $\left(\mathrm{C}_{\mathrm{D}}\right)$ between the cylinders and the surrounding flow. Simulations were performed considering Reynolds numbers of $\operatorname{Re}_{\mathrm{D}}=10,40$ and 150 and air as working fluid, i.e., Prandtl number is assumed $\mathrm{Pr}=0.71$. The problem presents three degrees of freedom: $\mathrm{S}_{\mathrm{T}} / \mathrm{D}$ (ratio between transversal pitch of the intermediate cylinders and the cylinders diameter), $\mathrm{S}_{\mathrm{L} 1} / \mathrm{D}$ (ratio between the frontal and intermediate cylinders longitudinal pitch and the cylinders diameter) and $\mathrm{S}_{\mathrm{L} 2} / \mathrm{D}$ (ratio between the intermediate and posterior cylinders longitudinal pitch and the cylinders diameter). However, $\mathrm{S}_{\mathrm{L} 1} / \mathrm{D}$ and $\mathrm{S}_{\mathrm{L} 2} / \mathrm{D}$ measures were kept fixed at 1.5 and $\mathrm{S}_{\mathrm{T}} / \mathrm{D}$ varies in the range $1.5 \leq \mathrm{S}_{\mathrm{T}} / \mathrm{D} \leq 5.0$. The conservation equations of mass, momentum and energy conservation are solved with the Finite Volume Method (FVM). Optimal results for fluiddynamic study in all $\mathrm{Re}_{\mathrm{D}}$ cases occurred for the lowest values of $S_{T} / D$, i.e., $\left(\mathrm{S}_{\mathrm{T}} / \mathrm{D}\right)_{\mathrm{o}, \mathrm{f}}=1.5$. For thermal analysis, $\mathrm{Nu}_{\mathrm{D}}$ behavior was assessed, where optimal results for $\mathrm{Re}_{\mathrm{D}}=10$ and 40 occurred for the highest values of $\mathrm{S}_{\mathrm{T}} / \mathrm{D}$, whilst, for $\mathrm{Re}_{\mathrm{D}}=150$, the optimal value was achieved for the intermediate ratio of $S_{T} / D=4.0$.

Keywords: forced convection; constructal design; geometric evaluation; external flows; staggered arrangement

Received: February 21, 2019

Revised: March 07, 2019

Accepted: April 08, 2019

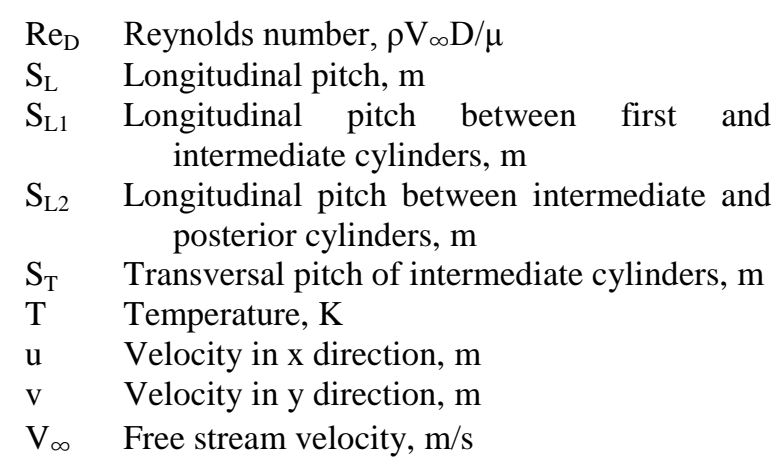

\section{Greek symbols}

$\alpha \quad$ Thermal diffusivity, $\mathrm{m}^{2} / \mathrm{s}$

$\mu \quad$ Dynamic viscosity, $\mathrm{kg} / \mathrm{m} . \mathrm{s}$

$v \quad$ Kinematic viscosity, $\mathrm{m}^{2} / \mathrm{s}$

$\rho \quad$ Density, $\mathrm{kg} / \mathrm{m}^{3}$

\section{Subscripts}

C1 Referent to cylinder 1 
C2 Referent to cylinder 2

C3 Referent to cylinder 3

C4 Referent to cylinder 4

F Referent to fluid dynamic problem

M Once maximized

m Once minimized

o Once optimized

sup Surface of cylinders

$\mathrm{T} \quad$ Referent to thermal problem

\section{INTRODUCTION}

The analysis of convection heat transfer flows is the focus of several studies in literature due to its applications in several equipment as heat exchangers, condensers, evaporators, cooling systems, refrigeration, power plants and others. These equipment are formed by arrays of cylinders and the geometrical configuration of these arrays can be evaluated to provide the best fluid dynamic and thermal performance (Çengel and Cimbala, 2006).

Recently, several important studies have been made concerned with geometrical evaluation of arrangements of cylinders/tubes subjected to convective flows. For instance, Pedrotti (2015) performed a geometric evaluation of a constructive array of tubes employing Constructal Design. The aim of the study was to construct one arrangement into an occupation area using a construction function in such way that maximizes the thermal performance of the arrangement. The forced convective flows were evaluated with different Reynolds numbers $\mathrm{Re}_{\mathrm{D}}$ $=10,50$ and 100, and Prandtl number $\operatorname{Pr}=0.71$. Four different minimum distances between the tubes were also evaluated: 1.00D, 1.25D, 1.50D and 2.00D. The obtained results showed that the imposition of a minimum distance and fluid flow intensity (measured by Reynolds number) influence the array formation. From the analysis, 1.5D restriction led to more thermal efficient arrays, in most cases.

Afterwards, Li et al. (2016) investigated forced convective heat transfer on cylinders with protrusions (protuberant regions). It is considered that cylinders have constant temperature and the fluid flow is heated by the cylinders. The influence of the height of the cylinders, alignment and number of protrusions in the heat transfer process were analyzed. The authors observed that the indentations between protrusions caused great deterioration in local heat transfer.

In Barros et al. (2017), the study of a triangular array of cylinders, submitted to mixed convection, was performed. In these simulations, Reynolds and Prandtl number were $\mathrm{Re}_{\mathrm{D}}=100$ and $\mathrm{Pr}=0.71$ and five different Richardson numbers in the range $0.1 \leq$ $\mathrm{Ri} \leq 10.0$. The study intended to assess the effects of Richardson number on both the drag coefficient $\left(C_{D}\right)$ and Nusselt number $\left(\mathrm{Nu}_{\mathrm{D}}\right)$ as well as over the effects of degrees of freedom over fluid dynamic and thermal performance indicators. The results obtained indicated that Richardson number values had great influence over the fluid dynamic and thermal behavior, as well as over $C_{D}$ and $\mathrm{Nu}_{D}$. For the analysis of $\mathrm{Nu}_{\mathrm{D}}$, with $\mathrm{Ri}=0.1$, maximization occurred at higher magnitudes for $\mathrm{S}_{\mathrm{T}} / \mathrm{D}=4.5$ and 5.0. While $\mathrm{Ri}=10.0$, intermediate ratio of $\mathrm{S}_{\mathrm{T}} / \mathrm{D}=2.5$ provided the best performance for both purposes.

In Pereira et al. (2017), a study with an array of four in-line cylinders, subject to forced convection, was performed using Constructal Design. $\mathrm{Re}_{\mathrm{D}}=100$ and two values for $\operatorname{Pr}=0.71$ and 5.83 were used in the simulations. The main purpose was to evaluate the effect of three degrees of freedom over drag coefficient $\left(C_{D}\right)$ and Nusselt number $\left(\mathrm{Nu}_{D}\right)$. The lowest magnitude of $\mathrm{S}_{\mathrm{T} 1} / \mathrm{D}$ (ratio between frontal transversal pitch and the cylinder diameters) $\mathrm{S}_{\mathrm{T} 1} / \mathrm{D}=$ 1.5 did not led to lowest magnitudes of $C_{D}$, which was not expected. The geometry that led to the lowest $\mathrm{C}_{\mathrm{D}}$ used $\mathrm{S}_{\mathrm{T} 2} / \mathrm{D}=2.0$ and $\mathrm{S}_{\mathrm{T} 1} / \mathrm{D}=1.5$. While for $S_{T 1} / D=3.0$ and 4.0 the geometries that led to the lowest $C_{D}$ were those from the aligned configuration where $S_{\mathrm{T} 2} / \mathrm{D}=3.0$ and 4.0 , considering $\mathrm{S}_{\mathrm{L}} / \mathrm{D}=1.5$. In general, Nusselt number followed the same tendency of the drag coefficient, i.e., it increased with the increase of transversal pitches, mainly for magnitudes of $\mathrm{S}_{\mathrm{T} 1} / \mathrm{D}$ and $\mathrm{S}_{\mathrm{T} 2} / \mathrm{D} \geq 2.5$.

In Seo et al. (2018), two-dimensional numerical simulations of free convective flows on a cold square enclosure containing four heated elliptical cylinders were performed. The obtained results showed that the aspect ratio (AR) of cylinders has a strong influence over heat transfer in cylinders and square enclosure surfaces.

In the present work, a four cylinders array configured in staggered form subjected to forced convective flows has its geometric configuration evaluated by means of Constructal Design (Bejan, 2000; Bejan and Lorente, 2008). One degree of freedom is evaluated in order to maximize Nusselt number $\left(\mathrm{Nu}_{\mathrm{D}}\right)$ and minimize the drag coefficient $\left(\mathrm{C}_{\mathrm{D}}\right)$ between the cylinders and the surrounding flow, keeping other degrees of freedom constant. Simulations were performed considering Reynolds numbers of $\operatorname{Re}_{\mathrm{D}}=10,40$ and 150 and Prandtl number of $\operatorname{Pr}=0.71$. Regarding the authors knowledge, there is no works related with application of Constructal Design for this kind of arrangement.

\section{PROBLEM DESCRIPTION}

The problem considers a laminar, incompressible, transient, two-dimensional forced convective flow over an arrangement of four staggered cylinders. The configuration of the arrangement is evaluated using Constructal Design method. Besides, all the cylinders have the same diameter, $\mathrm{D}=0.1 \mathrm{~m}$. The problem domain can be seen in Fig. 1 and its geometrical variables are: $\mathrm{L}=$ $35 \mathrm{D}=3.5 \mathrm{~m} ; \mathrm{H}=15 \mathrm{D}=1.5 \mathrm{~m} ; \mathrm{L}_{1}=8 \mathrm{D}=0.8 \mathrm{~m}, \mathrm{H}_{0}$ $=\mathrm{L}_{0}=6 \mathrm{D}=0.6 \mathrm{~m}, \mathrm{~A}_{0}=36 \mathrm{D}^{2}$. 
The flow is caused by imposition of constant velocity profile in the channel inlet (left surface) with velocities $\mathrm{V}_{\infty}$ that corresponds to Reynolds numbers of $\operatorname{Re}_{\mathrm{D}}=10,40$ and 150. A null manometric pressure (atmospheric) condition is imposed at the exit of domain (right surface). Symmetry condition is established on the lateral surfaces (symmetries 1 and 2). A no-slip and impermeability condition is imposed on the cylinder walls $\left(\mathrm{C}_{1}, \mathrm{C}_{2}, \mathrm{C}_{3}\right.$ and $\left.\mathrm{C}_{4}\right)$. For the thermal field, a prescribed temperature $\left(\mathrm{T}_{\mathrm{inf}}=\right.$ $300 \mathrm{~K})$ is imposed at the inlet and a higher temperature is imposed at the surfaces of cylinders $\left(\mathrm{T}_{\text {sup }}=320 \mathrm{~K}\right)$ causing the heat transfer between the cylinders and fluid flow.

Constructal Design methodology defines that, for geometrical evaluation, restrictions must be established to the problem (Bejan, 2000; Bejan and Zane, 2012). Thus, for this case, it is considered the following constraints: intermediate cylinders and cylinders diameter) and $\mathrm{S}_{\mathrm{L} 2} / \mathrm{D}$ (ratio between longitudinal pitch of intermediate and posterior cylinders and cylinders diameter). In the present study, the magnitudes of $\mathrm{S}_{\mathrm{L} 1} / \mathrm{D}$ and $\mathrm{S}_{\mathrm{L} 2} / \mathrm{D}$ are fixed at $\mathrm{S}_{\mathrm{L} 1} / \mathrm{D}=\mathrm{S}_{\mathrm{L} 2} / \mathrm{D}=1.5$, while $\mathrm{S}_{\mathrm{T}} / \mathrm{D}$ varies in the range $1.5 \leq \mathrm{S}_{\mathrm{T}} / \mathrm{D} \leq 5.0$, with increment of 0.5 .

Concerning the fluid dynamics purpose, the drag coefficient $\left(C_{D}\right)$ is taken into account as performance indicator and is given by (Bejan, 2013):

$$
C_{D}=\frac{F d}{\frac{1}{2} \rho V_{\infty}^{2} A}
$$

where $F_{\mathrm{d}}$ is the drag force $(\mathrm{N}), \rho$ is the density of the fluid $\left(\mathrm{kg} / \mathrm{m}^{3}\right), V_{\infty}$ is the free stream velocity $(\mathrm{m} / \mathrm{s})$ and A is the projected area of cylinder $(\mathrm{D} \times \mathrm{W})\left(\mathrm{m}^{2}\right)$ being $\mathrm{W}$ the depth of domain.

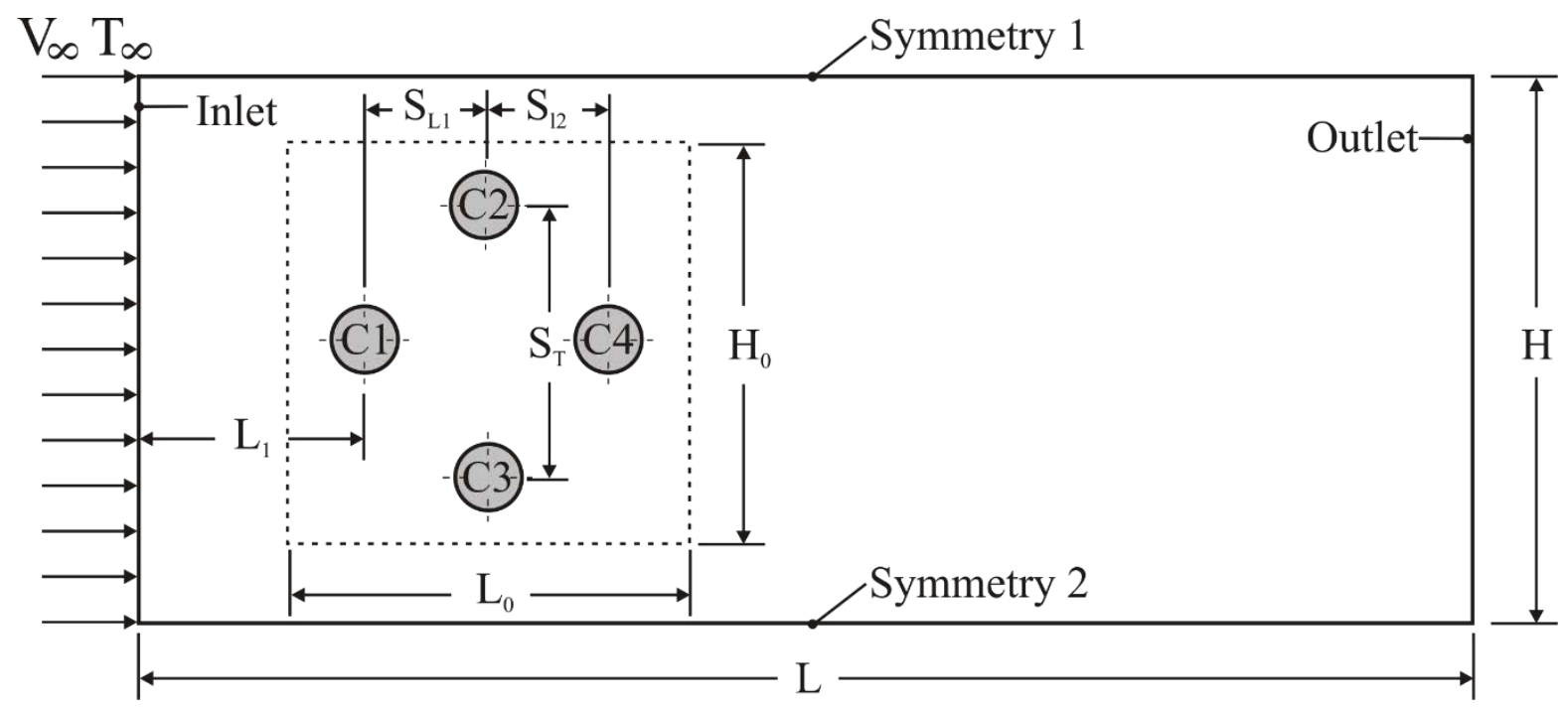

Figure 1. Computational domain of the staggered arrangement of cylinders.

i) The area of the four cylinders is the same in all cases, i.e., $A_{T}=A_{C 1}+A_{C 2}+A_{C 3}+A_{C 4}$;

ii) The diameters of all cylinders are the same: $\mathrm{D}=$ $\mathrm{D}_{1}=\mathrm{D}_{2}=\mathrm{D}_{3}=\mathrm{D}_{4}=1 \mathrm{~m}$;

iii) The occupation area of the arrangement of cylinders is defined as $\mathrm{A}_{0}=\mathrm{H}_{0} \times \mathrm{L}_{0}=36 \mathrm{D}^{2}$, considering that $\mathrm{H}_{0}=\mathrm{L}_{0}=6 \mathrm{D}$;

iv) Transversal spacing values between cylinders must not exceed the height of the occupation area of the cylinders, i.e., $\mathrm{S}_{\mathrm{T}}+\mathrm{D} \leq \mathrm{H}_{0}$;

v) Longitudinal spacing values between intermediate cylinders, plus the diameter, must not exceed the length of the occupation area of the cylinders, i.e., $\mathrm{S}_{\mathrm{L} 1}+\mathrm{S}_{\mathrm{L} 2}+\mathrm{D} \leq \mathrm{L}_{0}$

Concerning the configuration evaluation, the following degrees of freedom are defined: $\mathrm{S}_{\mathrm{T}} / \mathrm{D}$ (ratio between the transversal pitch of intermediate cylinders and cylinders diameter), $\mathrm{S}_{\mathrm{L} 1} / \mathrm{D}$ (ratio between longitudinal pitch of frontal and
For the thermal study, Nusselt number is used $\left(\mathrm{Nu}_{\mathrm{D}}\right)$, which physically represents the ratio between convection and conduction heat transfer in the analyzed surfaces. The time-averaged Nusselt number is given by (Bejan, 2013):

$$
N u_{D}=\frac{\bar{h} \cdot D}{K}
$$

where $\bar{h}$ is the time-averaged convection heat transfer $\left(\mathrm{W} /\left(\mathrm{m}^{2} . \mathrm{K}\right)\right)$, numerically estimated from the gradient of temperatures on the superficial region of each cylinder, $\mathrm{D}$ corresponds to the diameter of cylinders and $\mathrm{k}$ is the thermal conductivity of the fluid $(\mathrm{W} /(\mathrm{m} . \mathrm{K}))$.

Optimization process occurs through the evaluation of $\mathrm{S}_{\mathrm{T}} / \mathrm{D}$ pitch for constant $\mathrm{S}_{\mathrm{L} 1} / \mathrm{D}$ and $\mathrm{S}_{\mathrm{L} 2} / \mathrm{D}$, according to Fig. 2. Concerning the thermal 
problem, the highest magnitude of Nusselt number is named the once-maximized Nusselt number $\left(\mathrm{Nu}_{\mathrm{D}, \mathrm{M}}\right)$, and the corresponding geometry is named once optimized ratio of $\mathrm{S}_{\mathrm{T}} / \mathrm{D},\left(\mathrm{S}_{\mathrm{T}} / \mathrm{D}\right)_{\mathrm{o}, \mathrm{T}}$. For the fluiddynamic problem, the smallest $C_{D}$ will be the onceminimized $C_{D}\left(C_{D, m}\right)$, and the corresponding optimal geometry will be the once-optimized ratio $\left(\mathrm{S}_{\mathrm{T}} / \mathrm{D}\right)_{0}$.

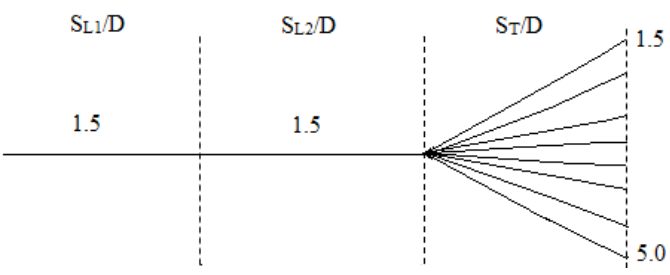

Figure 2. Flowchart illustrating the geometrical evaluation process by means of Constructal Design method.

\section{MATHEMATICAL AND NUMERICAL MODELING}

For the analysis of the heat transfer problem, with laminar, incompressible and transient flow, the following differential equations are used (Bejan, 2013):

- conservation equation of mass:

$$
\frac{\partial u}{\partial x}+\frac{\partial v}{\partial y}=0
$$

- conservation equation of momentum in $\mathrm{x}$ and y directions:

$$
\begin{aligned}
& \frac{\partial u}{\partial t}+u \frac{\partial u}{\partial x}+v \frac{\partial u}{\partial y}=-\frac{1}{\rho} \frac{\partial P}{\partial x}+v\left(\frac{\partial^{2} u}{\partial x^{2}}+\frac{\partial^{2} u}{\partial y^{2}}\right) \\
& \frac{\partial v}{\partial t}+u \frac{\partial v}{\partial x}+v \frac{\partial v}{\partial y}=-\frac{1}{\rho} \frac{\partial P}{\partial y}+v\left(\frac{\partial^{2} v}{\partial x^{2}}+\frac{\partial^{2} v}{\partial y^{2}}\right)
\end{aligned}
$$

- conservation equation of energy:

$$
\frac{\partial T}{\partial t}+u \frac{\partial T}{\partial x}+v \frac{\partial T}{\partial y}=\frac{k}{\rho C_{P}}\left(\frac{\partial^{2} T}{\partial x^{2}}+\frac{\partial^{2} T}{\partial y^{2}}\right)
$$

where $v$ is the dynamic viscosity $\left(\mathrm{m}^{2} / \mathrm{s}\right), \mathrm{x}$ and $\mathrm{y}$ represent spatial coordinates $(\mathrm{m}), \mathrm{u}$ and $\mathrm{v}$ are velocity components in $\mathrm{x}$ and $\mathrm{y}$ directions, $\mathrm{P}$ is the pressure $(\mathrm{Pa})$, $\mathrm{T}$ is temperature $(\mathrm{K})$ and $\mathrm{C}_{\mathrm{P}}$ is the specific heat at constant pressure (J/(kg.K)).

Equations (3) - (6) are solved via Computational Fluid Dynamics (CFD) by using the FLUENT version 14.0 software (Ansys, 2011), which is based on Finite Volumes method (Patankar, 1980; Versteeg and Malalasekera, 2007). With the spatial discretization being performed in rectangular and triangular volumes, time discretization is second- order implicit, and pressure-velocity coupling is solved by SIMPLEC algorithm.

The residuals of the conservation equations of mass, momentum and energy are considered converged when its magnitudes are lower than $10^{-6}$, $10^{-6}$ and $10^{-8}$, respectively.

Simulations were performed making use of computers with six-core Intel ${ }^{\circledR}$ Core TM i7 5820K @ $3.30 \mathrm{GHz}$ processors and $16 \mathrm{~GB}$ RAM. CFD Fluent ${ }^{\circledR}$ was configured to use 2 cores in each simulation through standard software MPI (Message Passing Interface) parallelism technique.

The grid-independent solution is performed with different triangular volumes: 71,300, 84,756, 113,524, 145,282 e 185,890, adopting a mesh independence criterium of $1.0 \times 10^{-3}$ for obtaining the time-averaged Nusselt number in the cylinder array. The 145.282 volumes mesh is considered as the independent case. It is worthy to mention that rectangular volumes with a higher refinement are employed in the near surfaces region to capture velocity and temperature gradients. Total processing time was approximately $2 \mathrm{~h}$ for each case, for $4 \mathrm{~s}$ of physical time.

\section{RESULTS AND DISCUSSION}

Figure 3 illustrates the effect of $S_{T} / D$ ratio over the mean $C_{D}$ for the four cylinders, i.e., $C_{D}=\left(C_{D 1}+\right.$ $\left.C_{D 2}+C_{D 3}+C_{D 4}\right) / 4$ for $\operatorname{Re}_{D}=10,40$ and 150. As expected, for all $\operatorname{Re}_{\mathrm{D}}$ values, the lowest $C_{D}$ value occurred for $S_{T} / D=1.5$, therefore an increase in $C_{D}$ value occurred with the increase of $S_{T} / D$.

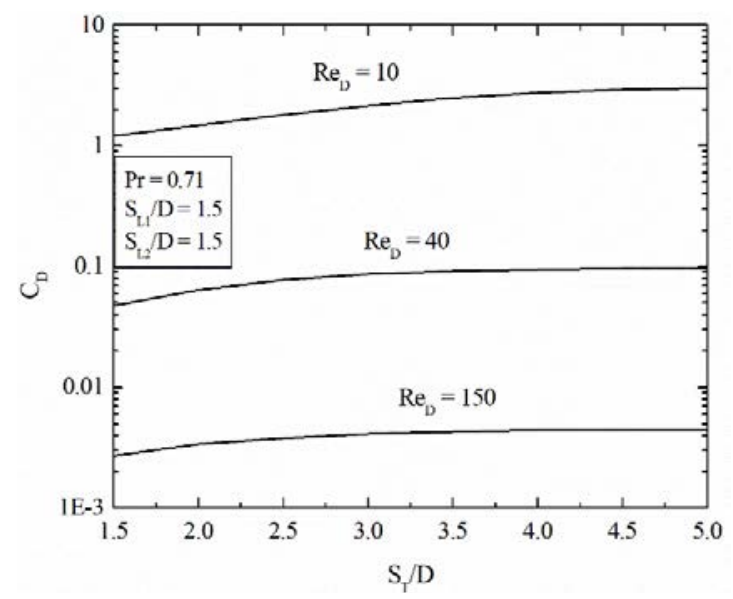

Figure 3. Effect of the ratio $\mathrm{S}_{\mathrm{T}} / \mathrm{D}$ over drag coefficient $\left(C_{D}\right)$ for three different Reynolds numbers $\left(\operatorname{Re}_{\mathrm{D}}=10,40\right.$ and 150) and $\mathrm{Pr}=0.71$.

Figure 4 shows the velocity and pressure fields for $\mathrm{Re}_{\mathrm{D}}=10$ when $\mathrm{S}_{\mathrm{T}} / \mathrm{D}=1.5$, Figs. 4(a) $-(\mathrm{b})$, and Figure 5 shows the same fields for $S_{T} / D=5.0$, Figs. 5(a) - (b). Results of Figs. 4 and 5 showed that for the lowest magnitude of $\mathrm{S}_{\mathrm{T}} / \mathrm{D}$ negative pressure is shared between two lateral cylinders and a positive pressure is noticed in front of the first cylinder, while 
for the highest magnitudes of $S_{T} / D$ it is observed a behavior similar to that noticed for a fluid flow over a solely cylinder, leading to an increase of $C_{D}$ for all $\mathrm{Re}_{\mathrm{D}}$ investigated.

Figures 6 and 7 show velocity and pressure fields when $\mathrm{Re}_{\mathrm{D}}=150$ and $\mathrm{S}_{\mathrm{T}} / \mathrm{D}=1.5$, Figs. 6(a) and (b), and $\mathrm{S}_{\mathrm{T}} / \mathrm{D}=5.0$, Figs. 7(a) and 7(b).

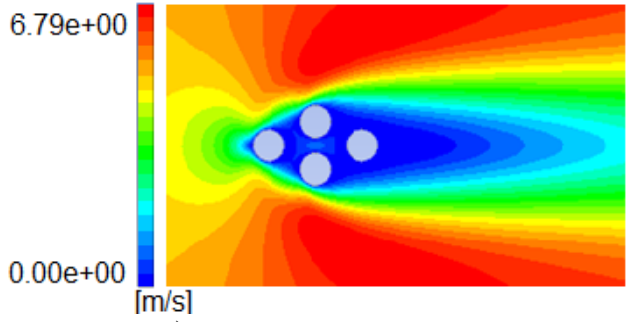

a)

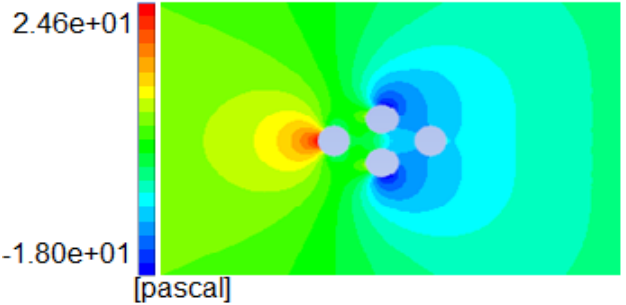

b)

Figure 4. Fields of air flow for $\mathrm{Re}_{\mathrm{D}}=10$ and $\mathrm{S}_{\mathrm{T}} / \mathrm{D}$ = 1.5: a) velocity field, $\mathrm{b}$ ) pressure field.

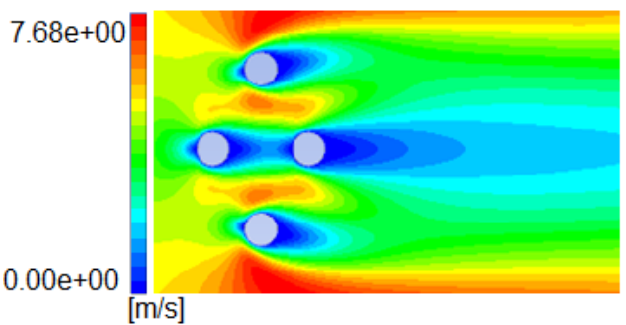

a)

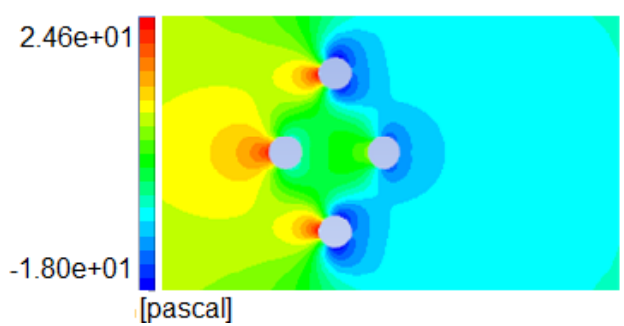

b)

Figure 5. Fields of air flow for $\mathrm{Re}_{\mathrm{D}}=10$ and $\mathrm{S}_{\mathrm{T}} / \mathrm{D}$

= 5.0: a) velocity field, $\mathrm{b}$ ) pressure field.

Results of Figs. 6 and 7 indicates that the free stream has a higher penetration in the middle of cylinders arrangement. Moreover, the downstream cylinder (C4) has higher pressure variation than that noticed for the case with $\operatorname{Re}_{\mathrm{D}}=10$. This behavior clearly is caused by the increase of fluid flow intensity. In spite of this fact, the effect of geometry over drag coefficient does not change from $\operatorname{Re}_{\mathrm{D}}=10$ to $\operatorname{Re}_{\mathrm{D}}=150$.

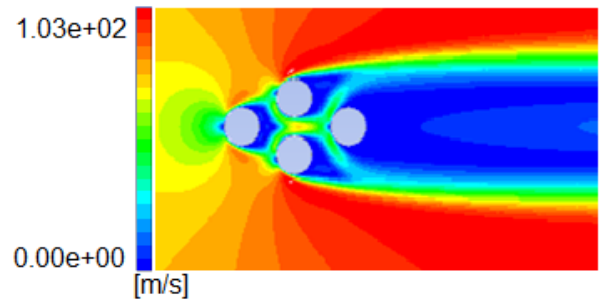

a)

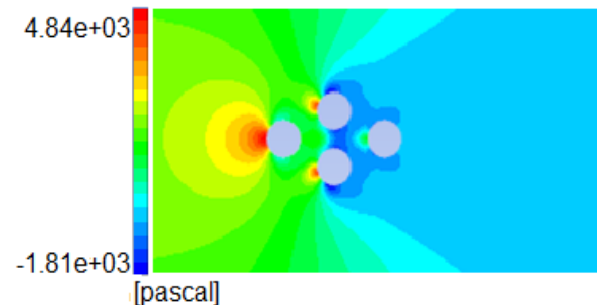

b)

Figure 6. Fields of air flow for $\operatorname{Re}_{\mathrm{D}}=150$ and $\mathrm{S}_{\mathrm{T}} / \mathrm{D}$ = 1.5: a) velocity field, $\mathrm{b}$ ) pressure field.

Figure 8 shows the effect of $\mathrm{S}_{\mathrm{T}} / \mathrm{D}$ over timeaveraged Nusselt number $\left(\mathrm{Nu}_{\mathrm{D}}\right)$ of four cylinders arrangement for $\mathrm{Re}_{\mathrm{D}}=10,40$ and 150. For $\mathrm{Re}_{\mathrm{D}}=10$ and 40, the optimal shapes are achieved for the highest magnitude of the ratio $\mathrm{S}_{\mathrm{T}} / \mathrm{D}$, i.e., $\left(\mathrm{S}_{\mathrm{T}} / \mathrm{D}\right)_{\mathrm{oT}}=$ 5.0. This behavior is mainly concerned with the interference of thermal boundary layers. Then, as more distant are the cylinders better is the heat exchange. For $\operatorname{Re}_{\mathrm{D}}=150$ an intermediate optimal ratio of $\mathrm{S}_{\mathrm{T}} / \mathrm{D}$ is obtained, $\left(\mathrm{S}_{\mathrm{T}} / \mathrm{D}\right)_{\mathrm{OT}}=4.0$. For this case, the increase of fluid flow magnitude leads to the optimal shape be achieved by a balance between thermal boundary layers interference and the amount of momentum near the cylinders. For the highest magnitude of $\mathrm{S}_{\mathrm{T}} / \mathrm{D}$, thermal boundary layers have the lowest interference, but the amount of momentum is not high enough than that reached for $\left(\mathrm{S}_{\mathrm{T}} / \mathrm{D}\right)_{\mathrm{OT}}=4.0$. In spite of this, there is no significant variation for $\mathrm{S}_{\mathrm{T}} / \mathrm{D} \geq 2.5$ when $\mathrm{Re}_{\mathrm{D}}=150$.

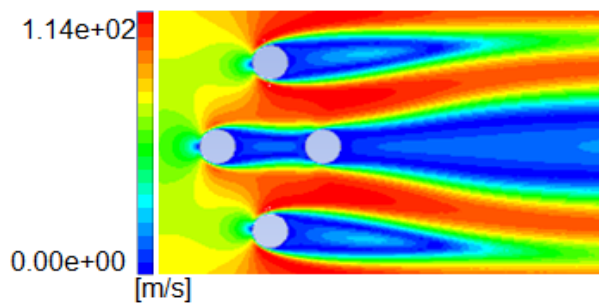

a)

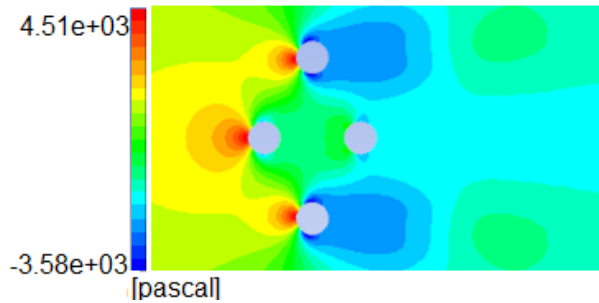

b)

Figure 7. Fields of air flow for $\operatorname{Re}_{\mathrm{D}}=150$ and $\mathrm{S}_{\mathrm{T}} / \mathrm{D}$ = 5.0: a) velocity field, $\mathrm{b}$ ) pressure field. 


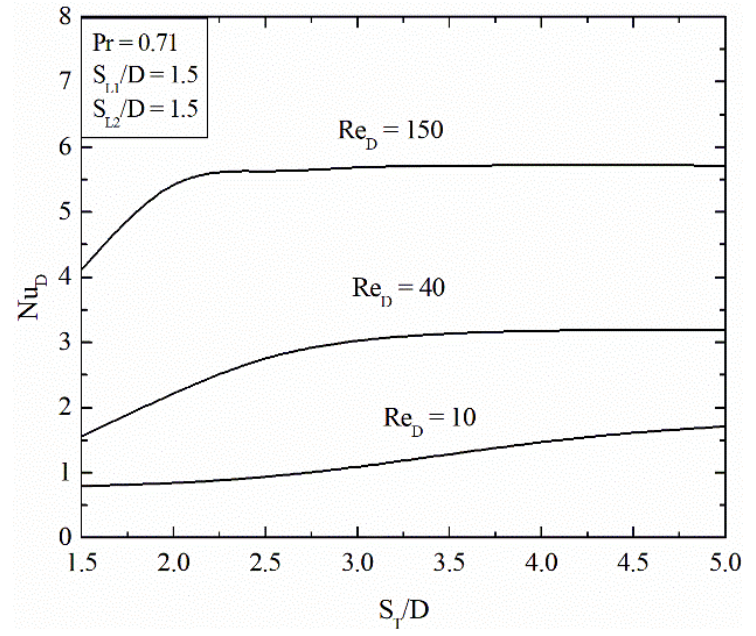

Figure 8. Effect of the ratio $\mathrm{S}_{\mathrm{T}} / \mathrm{D}$ over timeaveraged Nusselt number $\left(\mathrm{Nu}_{\mathrm{D}}\right)$ for three different Reynolds numbers $\left(\operatorname{Re}_{\mathrm{D}}=10,40\right.$ and 150) and $\mathrm{Pr}=$ 0.71 .

Figures 9 and 10 shows temperature fields for $\operatorname{Re}_{\mathrm{D}}=10$ when $\mathrm{S}_{\mathrm{T}} / \mathrm{D}=1.5$ and 5.0, Figs. 9(a) and 9(b), and $\mathrm{Re}_{\mathrm{D}}=150$ when $\mathrm{S}_{\mathrm{T}} / \mathrm{D}=1.5,4.0$ and 5.0, Figs. 10(a) - (c).

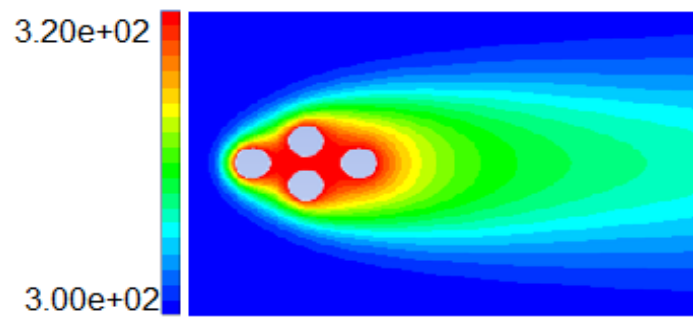

[K]

a)

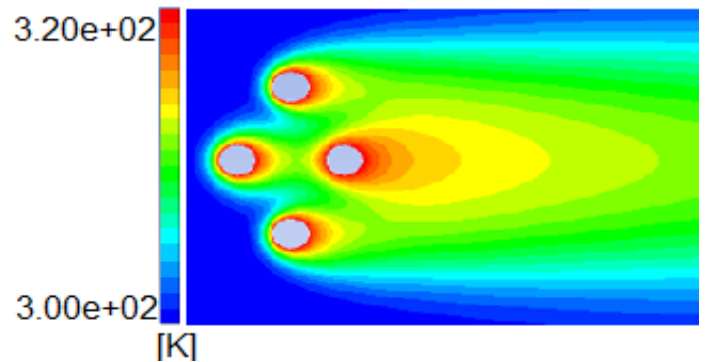

b)

Figure 9. Temperature field for $\operatorname{Re}_{\mathrm{D}}=10$ when:( a) $\mathrm{S}_{\mathrm{T}} / \mathrm{D}=1.5$, and $(\mathrm{b}) \mathrm{S}_{\mathrm{T}} / \mathrm{D}=5.0$.

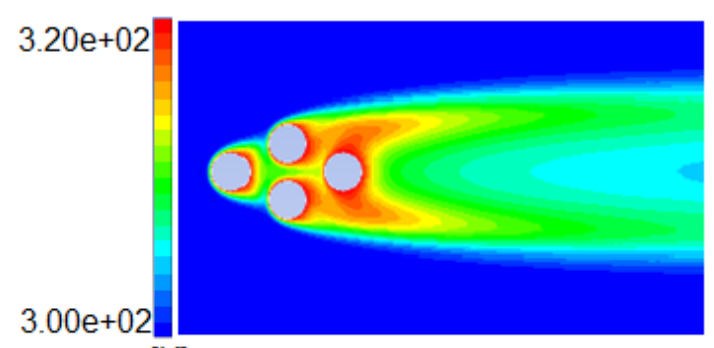

[K]

a)
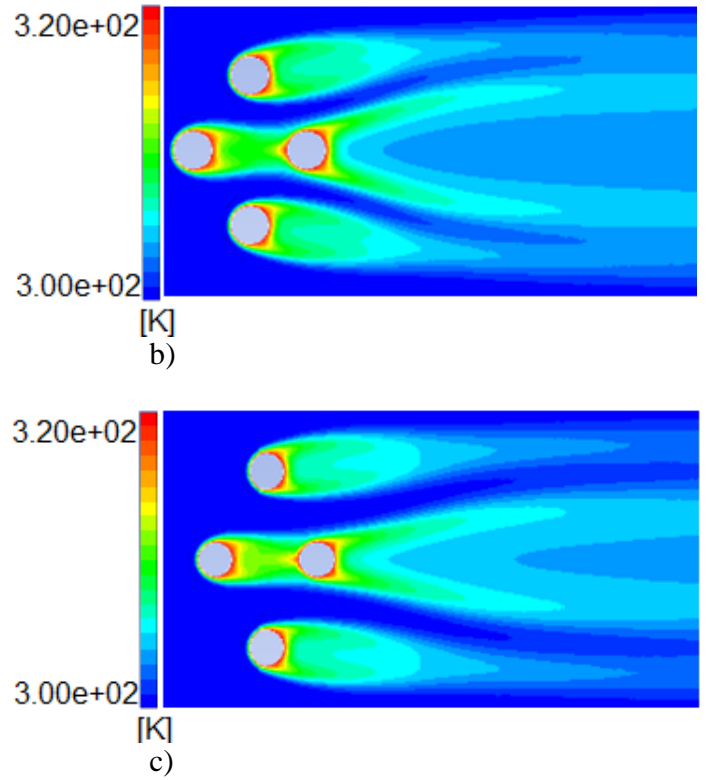

Figure 10. Temperature fields for $\operatorname{Re}_{\mathrm{D}}=150$ when: a) $\mathrm{S}_{\mathrm{T}} / \mathrm{D}=1.5$; b) $\left(\mathrm{S}_{\mathrm{T}} / \mathrm{D}\right)_{\mathrm{oT}}=4.0$ (optimal case); and c)

$$
\mathrm{S}_{\mathrm{T}} / \mathrm{D}=5.0 \text {. }
$$

For the $\mathrm{Re}_{\mathrm{D}}=10$ cases, it is noticed that cylinders grouping leads to a heating in the fluid surrounding the cylinders, directly affecting the Nusselt number. For $\mathrm{Re}_{\mathrm{D}}=40$ and 150 in $\mathrm{S}_{\mathrm{T}} / \mathrm{D}=1.5$ cases, the fluid flow is intensified in the gap between the cylinders, leading to a strong augmentation of Nusselt number for these $\mathrm{Re}_{\mathrm{D}}$. It can also be observed a preferential flow between central cylinders (C1 and C4) and lateral ones (C2 and C3). Figs.10(b) - (c) show that the gap between the central and lateral cylinders is more narrow for $\left(\mathrm{S}_{\mathrm{T}} / \mathrm{D}\right)_{\mathrm{oT}}=4.0$ than $\left(\mathrm{S}_{\mathrm{T}} / \mathrm{D}\right)=5.0$, leading to an augmentation of amount of momentum for $\left(\mathrm{S}_{\mathrm{T}} / \mathrm{D}\right)_{\mathrm{oT}}=$ 4.0 in comparison with $\mathrm{S}_{\mathrm{T}} / \mathrm{D}=5.0$.

\section{CONCLUSIONS}

Geometric evaluation of a four alternatecylinder array was performed in this work considering $\mathrm{Re}_{\mathrm{D}}=10$, 40 e 150 with $\operatorname{Pr}=0.71$, through Constructal Design Method, considering the following degrees of freedom: $\mathrm{S}_{\mathrm{L} 1} / \mathrm{D}$ and $\mathrm{S}_{\mathrm{L} 2} / \mathrm{D}$ fixed at 1.5 and $\mathrm{S}_{\mathrm{T}} / \mathrm{D}$ varied from 1.5 to 5.0 , with 0.5 increment.

According to the established objectives of $\mathrm{Nu}_{\mathrm{D}}$ maximization and $C_{D}$ minimization for the three cases in question. Optimal results for $\mathrm{Re}_{\mathrm{D}}=10$ and 40 occurred according to the expectance; the lowest $\mathrm{C}_{\mathrm{D}}$ resulted from the lowest $\mathrm{S}_{\mathrm{T}} / \mathrm{D}$, and the highest $\mathrm{S}_{\mathrm{T}} / \mathrm{D}$ values led to $\mathrm{Nu}_{\mathrm{D}}$ maximization, that is, $\left(\mathrm{S}_{\mathrm{T}} / \mathrm{D}\right)_{\mathrm{oT}}=5.0$.

For $\operatorname{Re}_{\mathrm{D}}=150, \mathrm{C}_{\mathrm{D}}$ occured at the lowest $\mathrm{S}_{\mathrm{T}} / \mathrm{D}$ value. Regarding $\mathrm{Nu}_{\mathrm{D}}$, the transversal pitch ratio that led to its maximization was $\left(\mathrm{S}_{\mathrm{T}} / \mathrm{D}\right)_{\mathrm{OT}}=4.0$. This happened due to flow momentum in the gap region between the central and lateral cylinders. For $\mathrm{S}_{\mathrm{T}} / \mathrm{D}=$ 
5.0, the increase in spacing possibly resulted in a decrease of flow intensity among the cylinders, resulting in a less intense temperature gradient. Furthermore, an increase in distance, from that point on, does not show much susceptibility to interact with other heated cylinders.

For future works, the authors intend to vary the degrees of freedom attributed values $\left(\mathrm{S}_{\mathrm{L} 1} / \mathrm{D}, \mathrm{S}_{\mathrm{L} 2} / \mathrm{D}\right.$ and $\mathrm{S}_{\mathrm{T}} / \mathrm{D}$ ), in order to obtain a geometry that contemplates $\mathrm{Nu}_{\mathrm{D}}$ maximization and $\mathrm{C}_{\mathrm{D}}$ minimization in a large range of geometrical possibilities.

\section{ACKNOWLEDGEMENTS}

A. P. Del Aghenese thanks CAPES for master science scholarship. Authors E. D. dos Santos, L. A. Isoldi and L. A. O. Rocha thank CNPq for research grants (Processes: 306024/2017-9, 306012/2017-0, 307847/2015-2). Author J. F. Prolo Filho thanks FAPERGS for research financial support.

\section{REFERENCES}

ANSYS. 14.0., 2011, FLUENT User's Guide, ANSYS Inc.

Barros, G. M., Lorenzini, G, Isoldi, L. A., Rocha, L. A. O. S., and Dos Santos, E. D., 2017, Influence of Mixed Convection Laminar Flows on the Geometrical Evaluation of a Triangular Arrangement of Circular Cylinders, International Journal of Heat and Mass Transfer, Vol. 114, pp. 1188-1200.

Bejan, A., 2013, Convection Heat Transfer, 4th Edition, Wiley.

Bejan, A., 2000, Shape and Structure, from Engineering to Nature, Cambridge University Press.

Bejan, A., and Lorente, S., 2008, Design with Constructal Theory, John Wiley \& Sons.

Bejan, A., and Zane, P., 2012, Design in Nature: How the Constructal Law Governs Evolution in Biology, Physics, Technology, and Social Organization, 1st ed., Doubleday.

Çengel, Y. A., and Cimbala, J. M., 2006, Fluid Mechanics: Fundamentals and Application, McGraw-Hill.

Li, S., Zhou, T., Sun, Z., and Dong, Z., 2016, External Forced Convection from Circular Cylinders with Surface Protrusions, International Journal of Heat and Mass Transfer, Vol. 99, pp. 20-30.

Patankar, S. V., 1980, Numerical Heat Transfer and Fluid Flow, McGraw Hill.

Pedrotti, V. A., 2015, Otimização Geométrica de Arranjos Tubulares Submetido a Escoamento Externo Utilizando Constructal Design, Master Thesis, Universidade Federal do Rio Grande-FURG, Rio Grande, RS. (in Portuguese)

Pereira, M. S., Feijó, B. C., Teixeira, F. B., Isoldi, L. A., Rocha, L. A. O., Goulart, J. N. V., and Dos Santos, E. D., 2017, Geometric Evaluation of
Forced Convective Flows Across an Arrangement of Four Circular Cylinders, Defect and Diffusion Forum, Vol. 372, pp. 110-121.

Seo, Y. M., Há, M. Y., and Park, Y. G., 2018, The Effect of Four Elliptical Cylinders with Different Aspect Ratios on the Natural Convection Inside a Square Enclosure, International Journal of Heat and Mass Transfer, Vol. 122, pp. 491-503.

Versteeg, H. K., and Malalasekera, W., 2007, An Introduction to Computational Fluid Dynamics: The Finite Volume Method, Pearson. 